\title{
A Swiss paradox? Higher income inequality of municipalities is associated with lower mortality in Switzerland
}

\author{
Kerri M. Clough-Gorr • Matthias Egger • \\ Adrian Spoerri
}

\begin{abstract}
It has long been surmised that income inequality within a society negatively affects public health. However, more recent studies suggest there is no association, especially when analyzing small areas. This study aimed to evaluate the effect of income inequality on mortality in Switzerland using the Gini index on municipality level. The study population included all individuals $>30$ years at the 2000 Swiss census $(\mathrm{N}=4,689,545)$ living in 2,740 municipalities with 35.5 million person-years of follow-up and 456,211 deaths over follow-up. Cox proportional hazard regression models were adjusted for age, gender, marital status, nationality, urbanization, and language region. Results were reported as hazard ratios (HR) with $95 \%$ confidence intervals. The mean Gini index across all municipalities was 0.377 (standard deviation 0.062 , range 0.202-0.785). Larger cities, high-income municipalities and tourist areas had higher Gini indices. Higher income inequality was consistently associated with lower mortality risk, except for death from external causes. Adjusting for sex, marital status, nationality, urbanization and
\end{abstract}

For the Swiss National Cohort Study Group.

K. M. Clough-Gorr $(\square) \cdot$ M. Egger · A. Spoerri Institute of Social and Preventive Medicine (ISPM), University of Bern, Finkenhubelweg 11, 3012 Bern, Switzerland e-mail: kerri.clough@ispm.unibe.ch

K. M. Clough-Gorr

Section of Geriatrics, Boston University Medical Center, Boston, MA, USA

M. Egger

School of Social and Community Medicine, University of Bristol, Bristol, UK language region only slightly attenuated effects. In fully adjusted models, hazards of all-cause mortality by increasing Gini index quintile were HR $=0.99(0.98-1.00), \mathrm{HR}=0.98$ (0.97-0.99), HR = $0.95(0.94-0.96), \mathrm{HR}=0.91(0.90-0.92)$ compared to the lowest quintile. The relationship of income inequality with mortality in Switzerland is contradictory to what has been found in other developed high-income countries. Our results challenge current beliefs about the effect of income inequality on mortality on small area level. Further investigation is required to expose the underlying relationship between income inequality and population health.

Keywords Income - Income inequality - Gini index · Mortality $\cdot$ Switzerland

\section{Introduction}

It has long been surmised that income inequality within a society negatively affects public health (for example [1-18]). The income inequality hypothesis IIH (i.e., income inequality has a negative effect on population health) has been well researched over the past decades by many studies using a variety of designs. Yet despite years of research the true effect of income inequality on population health, informed by findings of several literature reviews, remains uncertain $[1,3$, $4,19]$. A meta-analysis of multilevel studies showed a modest adverse effect of income inequality on mortality, stronger effects over longer follow-up and when incorporating timelags between inequality and mortality [9]. A systematic review of 98 studies categorizing the results into state-level, within-country aggregated studies and within-country multilevel studies. Lynch found, that on state-level the majority of the studies supported the IIH, whereas multilevel studies on lower level of aggregation showed null findings or mixed 
support of the IIH [1]. Similar results were found by others [3, 20, 21]. Studies not supporting the IIH tend to be studies analyzing smaller areas (e.g. municipalities) [3, 21, 22], which makes the unit of analyses a key issue in the analysis of income inequality and health [20]. Only very few studies reported a potential positive association between income inequality and health [21, 23]. Many of the issues related to studying income inequality and effects on health are confounded by heterogeneity of systemic and methodological factors (e.g. population characteristics, economic and political factors, accessibility and quality of health care and insurance, types of measures and outcomes used, area level of analysis) [10, 11]. Nonetheless, understanding if there truly is a systematic relation between higher income inequality and worse health with exploration of its mechanisms may provide important clues for targeted policy and clinical intervention.

Multiple theories have emerged to explain the negative association between income inequality and population health, specifically mortality [2, 3]. Two of the most commonly held theories are: (1) direct effects where poor persons living in areas of high income inequality have lower material living standards that influence health via worse living conditions, reduced access to health care and unhealthy lifestyles; and (2) contextual effects where a person feels poor relative to others in their community which erodes social cohesion and negatively influences health via psychosocial stress [24-26]. Theories for a no or positive association, on the other hand, are rare [21] and are explained by smaller areas not properly reflecting the social diversity of the population [3].

Income inequality and health is understudied in Switzerland but the unique characteristics of the country mean that it could make a meaningful contribution to the existing body of evidence. The average annual income in Switzerland is among the highest in Organization for Economic Co-operation and Development (OECD) countries and quality of life is high [27]. Switzerland has relatively little poverty $(7.6 \%$ of the population lived in poor households in 2011), a progressive tax structure, and a low unemployment rate (average $3.7 \%$ 2007-2012) [28]. Switzerland also has among the longest life expectancies; in 2012, life expectancy for males was 80.5 years, and for females was 84.7 years [28]. Healthcare is state-of-the-art, easily accessible, and health insurance is universally mandated and regulated by federal law.

The Gini index is a measure used worldwide to estimate income distribution. The OECD and World Bank list Switzerland's late-2000s Gini index at 0.28 and 0.34 , respectively [27, 29]. This is in line with its European neighbours and well below regions with the highest income inequality (notably, nations in Africa and South America which have a Gini Index of $\geq 0.50$ ) [27, 30]. But Switzerland has considerable geographic variability in income.
And according to the Swiss Federal Statistics Office (SFSO), the average disposable income of the wealthiest $20 \%$ of the population is 4.4-times greater than that of the lowest $20 \%$ (poorest) [28].

We analysed the Swiss National Cohort Study (SNC), a longitudinal cohort study of the entire Swiss population [31] to evaluate mortality according to income inequality at the level of municipalities. Our hypothesis was that mortality in Switzerland, as in other developed countries, would show no association or a weak increase with a higher Gini index.

\section{Materials and methods}

\section{Study population}

The SNC has been described in detail elsewhere [31]. In brief, deterministic and probabilistic record linkage connected census records to federal death or emigration records. Linkage was based on a set of key variables available in the linked datasets (e.g. sex, date of birth, place of residence, marital status, nationality). Because participation in the Swiss census is mandatory, enumeration is virtually complete: 2000 census coverage is estimated at $98.6 \%[28,31]$. We included all persons $\geq 30$ years old at the 2000 census. We excluded persons $<30$ years old because a smaller proportion of their deaths could be linked to census records [32].

\section{Variables and definitions}

The Gini index was calculated by the Swiss Federal Tax Administration (FTA) for 2740 Swiss municipalities using a Lorenz curve, based on estimated individual taxable income in 2003 [declared taxable income plus estimated tax deductions in Swiss Francs (CHF)]. All persons required to pay federal tax were included (i.e. residents and all non-residents owing property in Switzerland). Foreigners with short-term residence permits were excluded [33]. The Gini index measures income inequality on a $0-1$ scale [34, 35]. A coefficient of zero expresses perfect equality, where all values are the same (everyone has the same income) whereas a coefficient of one expresses maximal inequality (where one person has all the income). We categorized the Gini index based on quintiles of all persons included in the study population.

Socio-demographic data were based on census variables. Individual level variables included gender; age in years at census (continuous plus categories 30-44/45-59/60-74/7589/90+); marital status (single/married/widowed/divorced); and nationality (Swiss/non-Swiss). Geographic variables included urbanization (urban/peri-urban/rural), type of 
municipality (high-income/tourist/other) and language region (German/French/Italian). Type of municipality was based on the official SFSO hierarchical categorization of municipalities by income, predominant industry type, population density and distance from a major city [28]. The boundaries of the 2,740 Swiss municipalities were based on the 2003 official SFSO categorizations [28]. Municipalities' income (mean/median) was based on 2003 FTA data. Questionnaires and variable lists are available at www. swissnationalcohort.ch.

\section{Mortality}

Deaths and dates of death from all causes between date of census (5 December 2000) and end of follow-up (31 December 2008) were recorded from federally mandated death certificates. Since 1995, causes of death have been coded according to the tenth revision of the International Classification of Diseases, Injuries and Causes of Death (ICD-10). Causes of death were categorized based on ICD10 codes mentioned anywhere on the death certificate. Cause-specific deaths included cardiovascular diseases (ICD-10 I00-I99), all-cancer (ICD-10 C00-C97), suicide (ICD-10 X60-X84) and other external causes (ICD-10 V01-V99, W00-W99, X00-X59, X85-X99, Y00-Y98).

\section{Statistical analysis}

We obtained descriptive statistics (univariate, proportion, frequency) on all study variables. We calculated directstandardized age-adjusted mortality rates per quintile of Gini index using the whole analytic population as reference. We modelled the hazard ratio (HR) of death across quintiles of the Gini index using Cox proportional hazard regression models. We calculated time from date of birth and used age in years as the underlying timescale in all models. Time of observation was from the date of census to date of death, emigration, or end of follow-up whichever occurred first. Models were adjusted for age only, and age, gender, marital status, nationality, urbanization, language region based on their potential relation with independent and dependant variables [36, 37].

We did several additional analyses. To account for the multi-level structure of the data, we repeated all regression models with a random-effects Weibull model with shared frailty on municipality [38]. We also repeated our analyses using the 1995 Gini index and two alternative definitions of the 2003 index: declared taxable income only (without tax deductions) and declared taxable income adjusted for number of persons in household. We restricted analyses to the population of persons living within a municipality for five or more years. We reanalysed data using type of municipality and stratified by urbanization and language region. We additionally adjusted models for education (compulsory/secondary/tertiary/unknown), a neighbourhood index of socioeconomic position (SEP) [39], and income of municipalities. Lastly, we compared highest with lowest Gini index quintile for an expanded list of cause-specific deaths.

Results are reported as HRs with $95 \%$ confidence intervals $(95 \% \mathrm{CI})$. All analyses were done using Stata V12.1.

Ethics

Cantonal ethics committees of Bern and Zurich approved the SNC.

\section{Results}

Study population

The SNC includes 7,288,010 persons recorded at the 2000 census. We excluded 2,598,343 persons $(35.7 \%)<30$ years old at the time of census and 122 persons without follow-up (date of death or emigration same as date of census). Analyses were thus based on 4,689,545 persons with 35.5 million person-years of follow-up and 456,211 deaths over followup. The characteristics of the study population are listed in Table 1 . Almost $70 \%$ of the population was $<59$ years old and there were slightly more women than men (52.2 vs. $47.8 \%)$. The majority of the study population was married $(67.8 \%)$ and had Swiss nationality $(81.9 \%)$. Nearly $30 \%$ of the population lived in urban areas.

\section{Gini index}

The mean Gini index across all municipalities was 0.377 (standard deviation 0.062) and ranged from 0.202 to 0.785 . The lowest quintile included individuals living in communities with Gini indices ranging from 0.202 to 0.330 and the highest quintile from 0.416 to 0.785 (Table 1). Women, older people, single persons, foreigners and urban dwellers were more likely to live in municipalities with higher Gini indices. The proportion of persons from the French and Italian speaking regions of the country was highest in the fifth quintile (Table 1).

Figure 1 maps Gini index quintiles across municipalities. All larger cities had Gini indices within the two highest quintiles. Municipalities with higher Gini indices were also concentrated around the lakes (predominantly high-income communities) and in the mountainous regions (mainly tourist areas). Figure 2 shows a scatter plot of Gini indices against mean taxable income, stratified by type of municipality. High-income and tourist municipalities had 
Table 1 Characteristics of the study population $(\mathrm{N}=4,689,545)$ by Gini index quintile

\begin{tabular}{|c|c|c|c|c|c|}
\hline \multirow[t]{2}{*}{ Characteristic } & \multicolumn{5}{|l|}{ Gini index quintile } \\
\hline & $\begin{array}{l}0.202-0.330 \\
\mathrm{~N}(\%)\end{array}$ & $\begin{array}{l}0.331-0.353 \\
\mathrm{~N}(\%)\end{array}$ & $\begin{array}{l}0.354-0.379 \\
\mathrm{~N}(\%)\end{array}$ & $\begin{array}{l}0.380-0.415 \\
\mathrm{~N}(\%)\end{array}$ & $\begin{array}{l}0.416-0.785 \\
N(\%)\end{array}$ \\
\hline \multicolumn{6}{|l|}{ Age at census } \\
\hline $30-44$ years & $380,395(40.4)$ & $360,965(38.2)$ & $357,084(37.4)$ & $388,266(37.7)$ & $296,824(36.4)$ \\
\hline $45-59$ years & $292,340(31.0)$ & $294,615(31.2)$ & 299,995 (31.4) & $303,397(29.4)$ & $252,090(30.9)$ \\
\hline $60-74$ years & $177,906(18.9)$ & $187,063(19.8)$ & $194,569(20.4)$ & $208,584(20.2)$ & $169,840(20.8)$ \\
\hline $75-89$ years & $84,301(8.9)$ & $93,344(9.9)$ & $95,363(10.0)$ & $117,272(11.4)$ & 87,697 (10.7) \\
\hline $90+$ years & $7,446(0.8)$ & $8,578(0.9)$ & $8,856(0.9)$ & $12,803(1.2)$ & $9,952(1.2)$ \\
\hline \multicolumn{6}{|l|}{ Gender } \\
\hline Male & $464,119(49.2)$ & $456,116(48.3)$ & $457,084(47.8)$ & $482,395(46.8)$ & $383,877(47.0)$ \\
\hline Female & $478,269(50.8)$ & $488,449(51.7)$ & $498,783(52.2)$ & $547,927(53.2)$ & $432,526(53.0)$ \\
\hline \multicolumn{6}{|l|}{ Marital status } \\
\hline Single & $116,518(12.4)$ & $119,811(12.7)$ & 129,579 (13.6) & $194,444(18.9)$ & $134,398(16.5)$ \\
\hline Married & $681,904(72.4)$ & $665,898(70.5)$ & $661,043(69.2)$ & 638,199 (61.9) & $532,957(65.3)$ \\
\hline Widowed & $78,587(8.3)$ & $83,751(8.9)$ & $83,920(8.8)$ & $95,343(9.3)$ & $72,702(8.9)$ \\
\hline Divorced & $65,379(6.9)$ & $75,105(8.0)$ & $81,325(8.5)$ & $102,336(9.9)$ & $76,346(9.4)$ \\
\hline \multicolumn{6}{|l|}{ Nationality } \\
\hline Swiss & $811,057(86.1)$ & $792,536(83.9)$ & $791,734(82.8)$ & 823,242 (79.9) & $622,749(76.3)$ \\
\hline Other & $131,331(13.9)$ & $152,029(16.1)$ & $164,133(17.2)$ & $207,080(20.1)$ & $193,654(23.7)$ \\
\hline \multicolumn{6}{|l|}{ Urbanization } \\
\hline Urban & $28,077(3.0)$ & $149,624(15.8)$ & $242,624(25.4)$ & $642,424(62.4)$ & 301,610 (36.9) \\
\hline Peri-urban & $427,575(45.4)$ & $482,833(51.1)$ & $516,061(54.0)$ & 293,102 (28.4) & $392,322(48.1)$ \\
\hline Rural & $486,736(51.6)$ & $312,108(33.0)$ & $197,182(20.6)$ & $94,796(9.2)$ & $122,471(15.0)$ \\
\hline \multicolumn{6}{|l|}{ Language region } \\
\hline German & $761,323(80.8)$ & $753,890(79.8)$ & $673043(70.4)$ & 771,469 (74.9) & $421,385(51.6)$ \\
\hline French & $142,080(15.1)$ & $150,279(15.9)$ & $242582(25.4)$ & $236,220(22.9)$ & $317,221(38.9)$ \\
\hline Italian & $38,985(4.1)$ & $40,396(4.3)$ & $40242(4.2)$ & $22,633(2.2)$ & $77,797(9.5)$ \\
\hline Total & $942,388(100.0)$ & $944,565(100.0)$ & $955867(100.0)$ & $1,030,322(100.0)$ & $816,403(100.0)$ \\
\hline \multicolumn{6}{|c|}{ Deaths (mortality rate per 100,000 ) } \\
\hline All-cause & $85,196(1,325.3)$ & $91,001(1,314.9)$ & $92,102(1,286.0)$ & $108,689(1,293.4)$ & $79,223(1,199.3)$ \\
\hline Cardiovascular & $34,309(544.7)$ & $36,503(532.3)$ & $35,971(505.7)$ & $41,481(483.8)$ & $28,361(423.4)$ \\
\hline All-cancer & $22,695(341.2)$ & $23,547(334.4)$ & $24,180(331.1)$ & $26,355(324.8)$ & $20,929(324.0)$ \\
\hline Suicide & $1,442(20.4)$ & $1,544(21.6)$ & $1,571(21.6)$ & $1,984(25.1)$ & $1,421(22.7)$ \\
\hline External causes & $2,7,353$ (41.6) & 2,895 (41.7) & $2,876(40.2)$ & $3,612(43.2)$ & $2,607(40.0)$ \\
\hline
\end{tabular}

Swiss National Cohort, 2001-2008

the highest mean Gini indices ( 0.51 and 0.47 , respectively) and the highest and lowest mean taxable income (73,795 CHF and 29,680 CHF, respectively). Other municipalities mainly clustered below an estimated taxable income of 50,000 CHF and a Gini index of below 0.40.

Mortality by Gini index

Table 2 shows the association of Gini index quintile with all-cause and cause-specific mortality. All-cause mortality HRs decreased with increasing Gini indices $[\mathrm{HR}=0.99$
$(0.99-1.00), \quad \mathrm{HR}=0.98 \quad(0.97-0.99)], \quad \mathrm{HR}=0.95$ (0.94-0.96), HR $=0.91 \quad(0.90-0.92)$. For cardiovascular disease and all-cancer mortality similar associations were found. Suicide HRs were increased in the top two Gini index quintiles compared to the lowest but included the null $[\mathrm{HR}=1.09(1.01-1.18)$ and HR $=1.07(0.99-1.16)]$. For all other external causes no statistically significant differences were found by Gini index quintiles. Adjusting for mean or median tax income for each municipality did not materially change the association between the Gini index quintiles and all-cause mortality (Table 3 ). 


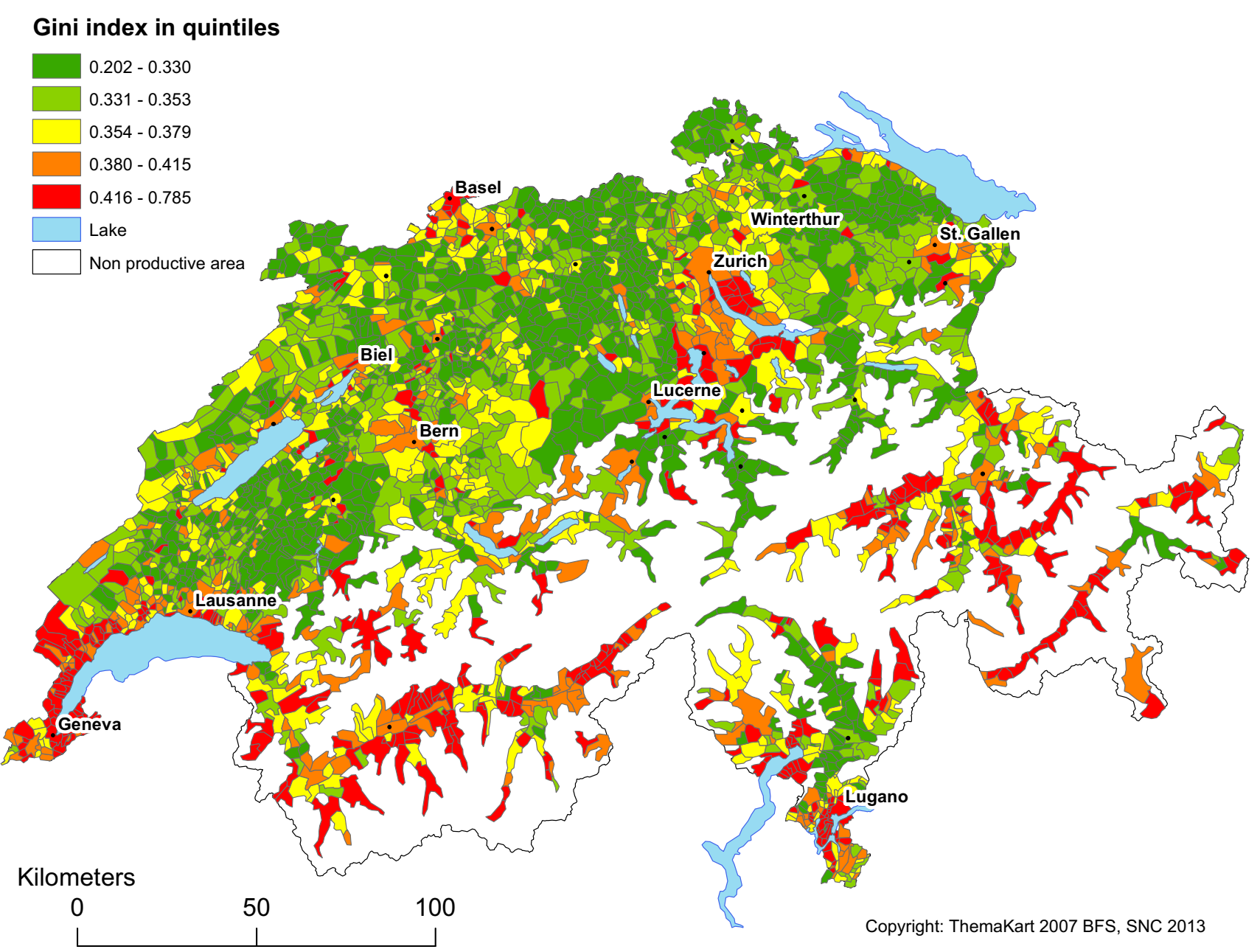

Fig. 1 Map of Switzerland showing Gini index quintiles for 2,740 municipalities. Swiss National Cohort

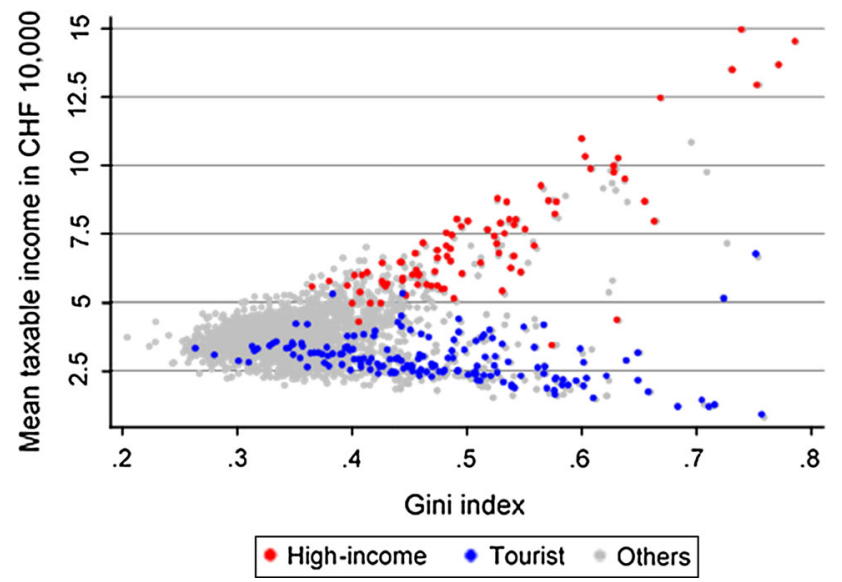

Fig. 2 Scatter plot of Gini index and mean taxable income for 2,740 Swiss municipalities by type of municipality

Additional analyses

For most of the additional causes of death analysed, mortality risk was lower in the highest Gini index quintile compared to the lowest, although many $95 \%$ CIs included the null
(Table S1). The overall study findings remained materially unchanged in additional analyses using shared frailty multilevel Weibull models, alternative Gini index measures, the subpopulation ( $\mathrm{N}=3,647,275)$ of persons living at least 5 years in the same municipality (Tables S2-S4). Analyses stratified by language region and urbanization were less consistent than our main findings and harder to interpret because of uncertainty due to smaller numbers of deaths (Tables S5-S6). Adjusting for type of municipality instead of urbanization did not materially change the results (Table S7). Adding area based SEP-index or, individual education to the models attenuated the HRs, but did not eliminate the association in the highest Gini index quintile (Table S8).

\section{Discussion}

Summary of main findings

Contrary to the results of earlier studies and our own hypothesis, we found that the relationship between income 
Table 2 Adjusted hazard ratios with $95 \%$ confidence intervals for all-cause, cardiovascular, all-cancer, suicide and other external cause mortality

\begin{tabular}{|c|c|c|c|c|c|}
\hline \multirow[t]{2}{*}{ Characteristic } & \multicolumn{5}{|c|}{ Hazard ratio ( $95 \%$ confidence interval) } \\
\hline & All-cause & Cardiovascular & All-cancer & Suicide & External causes \\
\hline \multicolumn{6}{|c|}{ Gini index quintile } \\
\hline $0.202-0.330$ & 1 & 1 & 1 & 1 & 1 \\
\hline $0.331-0.353$ & $\S \S$ & $0.99(0.98-1.01)$ & $0.98(0.96-1.00)$ & $1.04(0.97-1.12)$ & $1.01(0.96-1.07)$ \\
\hline $0.354-0.379$ & $0.98(0.97-0.99)$ & $0.97(0.96-0.99)$ & $0.97(0.95-0.99)$ & $1.02(0.94-1.09)$ & $0.98(0.93-1.04)$ \\
\hline $0.380-0.415$ & $0.95(0.94-0.96)$ & $0.91(0.89-0.92)$ & $0.92(0.91-0.94)$ & $1.09(1.01-1.18)$ & $1.02(0.97-1.08)$ \\
\hline $0.416-0.785$ & $0.91(0.90-0.92)$ & $0.85(0.83-0.86)$ & $0.93(0.91-0.95)$ & $1.07(0.99-1.16)$ & $0.99(0.93-1.04)$ \\
\hline \multicolumn{6}{|l|}{ Gender } \\
\hline Men & 1 & 1 & 1 & 1 & 1 \\
\hline Women & $0.57(0.56-0.57)$ & $0.57(0.57-0.58)$ & $0.55(0.54-0.55)$ & $0.39(0.37-0.41)$ & $0.48(0.47-0.50)$ \\
\hline \multicolumn{6}{|l|}{ Marital status } \\
\hline Single & $1.58(1.57-1.60)$ & $1.60(1.57-1.62)$ & $1.16(1.14-1.19)$ & $1.80(1.69-1.91)$ & $1.79(1.71-1.88)$ \\
\hline Married & 1 & 1 & 1 & 1 & 1 \\
\hline Widowed & $1.41(1.40-1.42)$ & $1.49(1.47-1.51)$ & $1.14(1.12-1.16)$ & $1.50(1.38-1.62)$ & $1.58(1.51-1.65)$ \\
\hline Divorced & $1.51(1.49-1.52)$ & $1.50(1.47-1.53)$ & $1.22(1.20-1.25)$ & $2.10(1.97-2.25)$ & $1.77(1.67-1.89)$ \\
\hline \multicolumn{6}{|l|}{ Nationality } \\
\hline Swiss & 1 & 1 & 1 & 1 & 1 \\
\hline Non-Swiss & $0.83(0.82-0.84)$ & $0.80(0.78-0.82)$ & $0.88(0.87-0.90)$ & $0.55(0.51-0.60)$ & $0.77(0.73-0.82)$ \\
\hline \multicolumn{6}{|l|}{ Urbanization } \\
\hline Urban & 1 & 1 & 1 & 1 & 1 \\
\hline Peri-urban & $0.99(0.98-1.00)$ & $1.06(1.05-1.08)$ & $0.96(0.94-0.97)$ & $0.85(0.80-0.91)$ & $1.04(0.99-1.09)$ \\
\hline Rural & $0.90(0.88-0.91)$ & $0.93(0.90-0.95)$ & $0.88(0.85-0.91)$ & $0.89(0.79-1.00)$ & $0.90(0.83-0.99)$ \\
\hline \multicolumn{6}{|c|}{ Language region } \\
\hline German & 1 & 1 & 1 & 1 & 1 \\
\hline French & $0.95(0.95-0.96)$ & $0.78(0.77-0.79)$ & $1.03(1.02-1.05)$ & $1.08(1.02-1.13)$ & $0.97(0.93-1.01)$ \\
\hline Italian & $0.90(0.89-0.91)$ & $0.80(0.78-0.82)$ & $1.09(1.06-1.12)$ & $0.57(0.49-0.65)$ & $0.83(0.77-0.90)$ \\
\hline
\end{tabular}

Swiss National Cohort, 2001-2008

Analyses based on 4,689,545 individuals. Cox proportional hazard models adjusted for all listed variables

inequality and mortality in Switzerland did not fit the expected pattern [1-18]. Higher income inequality in Switzerland was associated with lower all-cause mortality and mortality from major causes such as cardiovascular disease or cancer. This remained the case when we adjusted for individual or area-level socio-demographic variables. We also found notable geographic patterns of income disparity within Switzerland. Urban, tourist, and high-income communities tended to exceed the average national Gini index, and included municipalities with very high-income inequality. Our findings were robust in a broad range of stratified and sensitivity analyses.

Strengths and weaknesses of the study

Our study drew on a very large population base; the population of Swiss residents aged 30 years and older and selection bias can therefore be excluded. However, our findings cannot be generalized to those $<30$ years old. A limitation of the SNC is that linkage is generally less successful in younger adults who are a very mobile group [31]. Moreover, a previous study showed minimal effects from unlinked deaths on analyses of relative mortality [32]. The SNC also does not include data on individual financial resources, and so it was not possible to estimate the effects of individual income on mortality. Nevertheless, additional analyses that included municipality level tax information attenuated estimates but did not change our conclusions.

The Swiss Gini index also has some specific limitations that must be considered when it is used for research purposes. First, very low-income people may have a taxable income of less than zero after they add their estimated deductions to the total. These cases are recorded as zero income, which can in some cases make estimated income greater than actual income. Second, stock profits and capital gains are not taxable in Switzerland and some debts 
Table 3 Adjusted hazard ratios with $95 \%$ confidence intervals for all-cause mortality adjusting for mean and median tax per municipality
Swiss National Cohort, 2001-2008

Analyses based on 4,689,545 individuals. Cox proportional hazard models adjusted for age and all variables shown

\begin{tabular}{|c|c|c|c|}
\hline \multirow[t]{2}{*}{ Characteristic } & \multicolumn{3}{|c|}{ Hazard ratio (95\% confidence interval) } \\
\hline & Model I & Model II & Model III \\
\hline \multicolumn{4}{|c|}{ Gini index quintile } \\
\hline $0.202-0.330$ & 1 & 1 & 1 \\
\hline $0.331-0.353$ & $0.99(0.99-1.00)$ & $1.00(0.99-1.01)$ & $0.99(0.98-1.00)$ \\
\hline $0.354-0.379$ & $0.98(0.97-0.99)$ & $0.99(0.98-1.00)$ & $0.98(0.97-0.99)$ \\
\hline $0.380-0.415$ & $0.95(0.94-0.96)$ & $0.97(0.96-0.98)$ & $0.96(0.95-0.97)$ \\
\hline $0.416-0.785$ & $0.91(0.90-0.92)$ & $0.96(0.95-0.98)$ & $0.93(0.92-0.94)$ \\
\hline \multicolumn{4}{|c|}{ Mean tax quintiles (per 10,000 CHF) } \\
\hline $0.9-3.6$ & & 1 & \\
\hline $3.7-3.9$ & & $1.00(0.99-1.01)$ & \\
\hline $4.0-4.2$ & & $0.97(0.96-0.97)$ & \\
\hline $4.3-4.6$ & & $0.97(0.96-0.98)$ & \\
\hline $4.7-15.0$ & & $0.89(0.88-0.90)$ & \\
\hline \multicolumn{4}{|c|}{ Median tax quintiles (per 10,000 CHF) } \\
\hline $0.2-3.3$ & & & 1 \\
\hline $3.4-3.5$ & & & $0.98(0.97-0.99)$ \\
\hline $3.6-3.7$ & & & $0.97(0.96-0.98)$ \\
\hline $3.8-4.0$ & & & $0.96(0.95-0.97)$ \\
\hline $4.1-6.3$ & & & $0.90(0.89-0.91)$ \\
\hline \multicolumn{4}{|l|}{ Gender } \\
\hline Men & 1 & 1 & 1 \\
\hline Women & $0.57(0.56-0.57)$ & $0.57(0.56-0.57)$ & $0.57(0.56-0.57)$ \\
\hline \multicolumn{4}{|l|}{ Marital status } \\
\hline Single & $1.58(1.57-1.60)$ & $1.58(1.57-1.60)$ & $1.58(1.57-1.60)$ \\
\hline Married & 1 & 1 & 1 \\
\hline Widowed & $1.41(1.40-1.42)$ & $1.41(1.40-1.42)$ & $1.41(1.40-1.42)$ \\
\hline Divorced & $1.51(1.49-1.52)$ & $1.51(1.49-1.52)$ & $1.51(1.49-1.52)$ \\
\hline \multicolumn{4}{|l|}{ Nationality } \\
\hline Swiss & 1 & 1 & 1 \\
\hline Non-Swiss & $0.83(0.82-0.84)$ & $0.83(0.82-0.84)$ & $0.83(0.82-0.84)$ \\
\hline \multicolumn{4}{|l|}{ Urbanization } \\
\hline Urban & 1 & 1 & 1 \\
\hline Peri-urban & $0.99(0.98-1.00)$ & $0.97(0.96-0.98)$ & $0.97(0.97-0.98)$ \\
\hline Rural & $0.90(0.88-0.91)$ & $0.98(0.97-0.99)$ & $0.98(0.97-0.99)$ \\
\hline \multicolumn{4}{|c|}{ Language region } \\
\hline German & 1 & 1 & 1 \\
\hline French & $0.95(0.95-0.96)$ & $0.96(0.95-0.96)$ & $0.95(0.94-0.96)$ \\
\hline Italian & $0.90(0.89-0.91)$ & $0.88(0.87-0.90)$ & $0.87(0.86-0.89)$ \\
\hline
\end{tabular}

(e.g. real estate) are tax deductible. Thus, the estimated taxable income of persons with these types of investments and liabilities may be inaccurate. We also might have underestimated wealth of foreigners who own second homes in Switzerland because income reports that rely solely on Swiss property income grossly underestimate their true income. However, our additional analyses removed the tourist communities where the majority of foreigners own second homes, so we do not think this had an effect on our findings.
Results in context with other studies

To the best of our knowledge, no other study analysing a nearly complete population has found higher income inequality to be consistently associated with lower mortality. Reviews on income inequality and health have categorized published studies as either "supportive," "mixed," or "unsupportive" [1, 3, 4]. In their review of over 150 published studies (including 168 separate analyses), Wilkinson et al. [3] found that $70 \%$ of studies either 
supported or partially supported a positive association. Zheng's evaluation of 79 studies also indicated general support for the income inequality hypothesis, and emphasized that the timing of income inequality measurement and mortality affects play an important role [4]. Both reviews found stronger support in studies with larger analysis areas, and less evidence from those with smaller geographical aggregation (e.g. cities, states). A meta-analysis of 28 studies showed an $8 \%$ excess mortality risk per 0.05 Gini index unit increase, and also indicated that timing of income equality in relation to mortality affects associations [9]. The evidence is mixed, but it tends to support the income inequality hypothesis when inequality precedes mortality and larger analysis areas are considered. We saw no effects related to timing, possibly because in Switzerland the Gini index has been relatively stable over time (Gini index 0.39 in 1995, 0.38 in 2003). Very few studies to date have presented evidence that challenges the income inequality hypothesis. Two reviews did include a small number of studies that suggested that some outcomes improved with greater inequality, but other outcomes did not and results were often limited to specific groups (e.g. women living outside main cities) [1,3]. When study results contradicted the income inequality hypothesis, this was generally explained by poor methodology $[18,20,23$, 40-42]. For example, when Wen et al. [42] found a positive association between the Gini index and self-rated health in multilevel models, they described it as a product of confounding by aggregated education. Lorant et al. [23] found that mortality decreased with unequal income distribution but argued that this was caused by uncontrolled confounding due to profession and/or unexplained differences in country-specific social and political characteristics.

\section{Possible mechanisms}

Kravdal hypothesized that results that conflict with the income inequality hypothesis are conceivable in higher income countries that have a progressive tax structure (like Switzerland) [21]. If overall income is high, even if income inequality exists, these communities may invest in infrastructures (for example public swimming pools or other sports amenities) that benefit the public's health. Furthermore, in this situation the high Gini index is a product of comparisons between persons with moderate incomes versus high and extremely high incomes, rather than between persons with low incomes versus higher incomes. This may be a less divisive social stratification than low versus high-income, and also be less likely to affect social cohesion. The use of tax revenue for the public good in wealthy communities with a progressive tax structure, combined with some degree of social cohesion in country with a direct democracy might at least in part explain the apparent Swiss paradox of higher Gini index and lower mortality risk.

There are several other factors that might also explain why Switzerland's results are different from other developed countries. First, when overall mortality is low (Switzerland has very high life expectancy) there may be added health benefits (e.g. increased preventative health spending) from the tax revenues paid by the very wealthy living in high-income municipalities. Second, there is a potential interrelationship between public health infrastructure, income inequality and disease-related mortality. Deaths from external causes are less likely to reflect the health of the general population or public health infrastructures. In this study, deaths from external causes showed inconsistent associations with income inequality hinting at such an interrelationship in Switzerland. Studies of external causes of death in other countries are scares. Third, federally mandated health insurance in Switzerland ensures access to basic healthcare, but income-differentiated access to supplemental healthcare (e.g. senior level treating physicians, choice of hospital, preventative and alternative healthcare, etc.) might result in improved health outcomes for the wealthy. If more persons with supplemental insurance live in areas with high Gini index then it might help to explain the differences in mortality by Gini index seen in this study. Unfortunately the data needed to test this hypothesis was not available in the SNC. Although findings from a recent study suggested regional differences probably reflected the inappropriate use of specialist care, rather than differential access to care in general [43]. Lastly, Switzerland has the highest life satisfaction ranking of all OECD countries [27]. It is conceivable that a person who rates their life satisfaction high is also less likely to feel poor relative to others (i.e., proxy for strong social cohesion). If municipalities with high Gini index also have high life satisfaction ratings (data is not available by municipality) then this might also contribute to these Swiss findings conflicting with the income inequality hypothesis.

We cannot exclude the possibility that residual confounding in the study contributed to the positive association between income inequality and health. Unmeasured characteristics of the municipalities (e.g. agriculture at a small scale in mountain areas with moderate differences in income, or urban areas with mainly jobs in the service sector with the potential of well-paid jobs in private businesses) as well as environmental or cultural characteristics may play an important role [21]. However, we adjusted for the diversity of the municipalities by including an urbanization variable (Table 2), types of municipalities (Table S7) and for potential cultural differences by including the three main Swiss language regions (Table 2) to minimize potential residual confounding. Further, we adjusted for the unmeasured characteristics of municipalities and the multi- 
level characteristic of the study data using random-effects Weibull models with shared frailty on the municipalities. The association between income inequality and mortality did not change materially (Table S2). Additionally, reverse causality might affect the inequality-mortality association. Persons with severe health problems might drop out of their employment and therefore account for very low incomes which might increase the income inequality. However, our study has a retrospective cohort design with a follow-up of up to 8 years, where the exposition to the inequality occurred before death. In table S3 we showed that using the Gini index from 1995 and in table S4 that restricting the study population to persons who had lived five or more years prior to the census in the same municipality did not change the association between the income inequality and mortality.

Our findings suggest a path for future research: What makes Switzerland different from other developed highincome countries? In Switzerland, why is higher income inequality associated with lower mortality? Although we propose some explanations for this unusual result, the underlying factors that affect the relationship between income inequality and population health have not yet been elucidated. We suggest that future research on this question should consider the role of infrastructures and access to health care. It should also include measures of individual resources (e.g. income and/or wealth) because they might allow clearer distinctions between direct and contextual income effects.

\section{Conclusions}

Although it is widely accepted that there is either a correlation between higher income inequality and poorer health or that there is no association, we found that in Switzerland the higher the inequality the better the health was true. This indicates that the relationship between income inequality and health, and the factors that influence it, has yet to be fully understood.

Acknowledgments This manuscript contains original material not
previously published. We thank the Swiss Federal Statistical Office
for providing mortality and census data and for the support which
made the Swiss National Cohort and this study possible. This work
was supported by the Swiss National Science Foundation (Grant Nos.
3347CO-108806, 33CS30_134273 and 33CS30_148415). The mem-
bers of the Swiss National Cohort Study Group are Matthias Egger
(Chairman of the Executive Board), Adrian Spoerri and Marcel
Zwahlen (all Bern), Milo Puhan (Chairman of the Scientific Board)
and Matthias Bopp (both Zurich), Nino Künzli (Basel), Fred Paccaud
(Lausanne) and Michel Oris (Geneva). We also thank Kali Tal for her
editorial contribution and Rudi Peters from the FTA for his helpful
comments. This work was supported by funds from the Swiss
National Science Foundation (Grant Number 33CSC0_134273). The sponsors had no role in study design, methods, data collection, analysis, or paper preparation.

Conflict of interest None of the authors has a conflict of interest.

\section{References}

1. Lynch J, Smith GD, Harper S, et al. Is income inequality a determinant of population health? Part 1, A systematic review. Milbank Q. 2004;82:5-99.

2. Wagstaff A, van Doorslaer E. Income inequality and health: what does the literature tell us? Annu Rev Public Health. 2000;21:543-67.

3. Wilkinson RG, Pickett KE. Income inequality and population health: a review and explanation of the evidence. Soc Sci Med. 2006;62:1768-84.

4. Zheng H. Do people die from income inequality of a decade ago? Soc Sci Med. 2012;75:36-45.

5. Zheng H, Rising US. income inequality, gender and individual self-rated health, 1972-2004. Soc Sci Med. 2009;69:1333-42.

6. Shibuya K, Hashimoto H, Yano E. Individual income, income distribution, and self rated health in Japan: cross sectional analysis of nationally representative sample. BMJ. 2002;324:16-9.

7. Kennedy BP, Kawachi I, Glass R, Prothrow-Stith D. Income distribution, socioeconomic status, and self rated health in the United States: multilevel analysis. BMJ. 1998;317:917-21.

8. Kahn RS, Wise PH, Kennedy BP, Kawachi I. State income inequality, household income, and maternal mental and physical health: cross sectional national survey. BMJ. 2000;321:1311-5.

9. Kondo N, Sembajwe G, Kawachi I, et al. Income inequality, mortality, and self rated health: meta-analysis of multilevel studies. BMJ. 2009;339:b4471.

10. Judge K, Mulligan JA, Benzeval M. Income inequality and population health. Soc Sci Med. 1998;46:567-79.

11. De Maio FG. Ecological analysis of the health effects of income inequality in Argentina. Public Health. 2008;122:487-96.

12. Ben-Shlomo Y, White IR, Marmot M. Does the variation in the socioeconomic characteristics of an area affect mortality? BMJ. 1996;312:1013-4.

13. Blakely T, Atkinson J, O'Dea D. No association of income inequality with adult mortality within New Zealand: a multi-level study of 1.4 million 25-64 year olds. J Epidemiol Community Health. 2003;57:279-84.

14. Dahl E, Ivar Elstad J, Hofoss D, Martin-Mollard M. For whom is income inequality most harmful? A multi-level analysis of income inequality and mortality in Norway. Soc Sci Med. 2006;63:2562-74.

15. Judge K. Income distribution and life expectancy: a critical appraisal. BMJ 1995; 311: 1282-1285; discussion 1285-1287.

16. Kaplan GA, Pamuk ER, Lynch JW, et al. Inequality in income and mortality in the United States: analysis of mortality and potential pathways. BMJ. 1996;312:999-1003.

17. Kennedy BP, Kawachi I, Prothrow-Stith D. Income distribution and mortality: cross sectional ecological study of the Robin Hood index in the United States. BMJ. 1996;312:1004-7.

18. Lynch J, Smith GD, Hillemeier M, et al. Income inequality, the psychosocial environment, and health: comparisons of wealthy nations. Lancet. 2001;358:194-200.

19. Wagstaff A, Doorslaer E. Income Inequality and Health: what does the literature tell us? Annu Rev Public Health. 2000;21:543-67.

20. Osler M, Christensen U, Due P, et al. Income inequality and ischaemic heart disease in Danish men and women. Int J Epidemiol. 2003;32:375-80. 
21. Kravdal O. Does income inequality really influence individual mortality? Results from a 'fixed-effects analysis' where constant unobserved municipality characteristics are controlled. Demogr Res. 2008;18:205-32.

22. Subramanian SV, Kawachi I. Income inequality and health: What have we learned so far? Epidemiol Rev. 2004;26:78-91.

23. Lorant V, Thomas I, Deliege D, Tonglet R. Deprivation and mortality: the implications of spatial autocorrelation for health resources allocation. Soc Sci Med. 2001;53:1711-9.

24. Kawachi I, Kennedy BP. Health and social cohesion: why care about income inequality? BMJ. 1997;314:1037-40.

25. Kondo N. Socioeconomic disparities and health: impacts and pathways. J Epidemiol. 2012;22:2-6.

26. Wilkinson RG, Pickett KE. The problems of relative deprivation: why some societies do better than others. Soc Sci Med. 2007;65:1965-78.

27. OECD Better Life Index. In. Paris, France: organisation for economic co-operation and development (OECD) 2013.

28. Topics, Basics and Overviews. In 2013 Edition. Neuchatel, Switzerland: Swiss Federal Statistics Office (SFSO) 2013.

29. Data Catalog. In. Washington DC, USA: The World Bank Group 2013.

30. The World Factbook. In. Washington DC, USA: The Central Intellegence Agency 2013.

31. Spoerri A, Zwahlen M, Egger M, Bopp M. The Swiss National Cohort: a unique database for national and international researchers. Int J Public Health. 2010;55:239-42.

32. Schmidlin K, Clough-Gorr KM, Spoerri A, et al. Impact of unlinked deaths and coding changes on mortality trends in the Swiss National Cohort. BMC Med Inform Decis Mak. 2013;13:1.
33. Jeitziner B, Peters R. Regionale Einkommens- und Vermögensverteilung in der Schweiz. In. Bern, Switzerland: Swiss Federal Tax Administration (SFTA) 2009.

34. Regidor E. Measures of health inequalities: part 1. J Epidemiol Community Health. 2004;58:858-61.

35. Lorenz MO. Methods of measuring the concentration of wealth. Publ Am Stat Assoc. 1905;9:209-19.

36. Panczak R, Spoerri A, Zwahlen M, et al. Religion and suicide in patients with mental illness or cancer: Swiss National Cohort study. Suicide Life Threat Behav. 2013;43:213-22.

37. Spoerri A, Schmidlin K, Richter M, et al. Individual and spousal education, mortality and life expectancy in Switzerland: a national cohort study. J Epidemiol Community Health. 2014;68:804-10.

38. Clark TG, Bradburn MJ, Love SB, Altman DG. Survival analysis part IV: further concepts and methods in survival analysis. $\mathrm{Br} \mathrm{J}$ Cancer. 2003;89:781-6.

39. Panczak R, Galobardes B, Voorpostel M, et al. A Swiss neighbourhood index of socioeconomic position: development and association with mortality. J Epidemiol Community Health. 2012;66:1129-36.

40. McLeod CB, Lavis JN, Mustard CA, Stoddart GL. Income inequality, household income, and health status in Canada: a prospective cohort study. Am J Public Health. 2003;93:1287-93.

41. Pampel FC. Inequality, diffusion, and the status gradient in smoking. Soc Probl. 2002;49:35-57.

42. Wen M, Browning CR, Cagney KA. Poverty, affluence, and income inequality: neighborhood economic structure and its implications for health. Soc Sci Med. 2003;57:843-60.

43. Busato A, Matter P, Kunzi B, Goodman D. Geographic variation in the cost of ambulatory care in Switzerland. J Health Serv Res Policy. 2012;17:18-23. 